\title{
Modified graphite electrodes as potential cathodic electrocatalysts for microbial electrolysis cells
}

\author{
E. Chorbadzhiyska ${ }^{1,2^{*}}$, I. Bardarov ${ }^{1,2}$, Y. Hubenova ${ }^{3,4}$, M. Mitov ${ }^{1,2}$ \\ ${ }^{1}$ Department of Chemistry, South-West University, Blagoevgrad, Bulgaria \\ ${ }^{2}$ Innovative Centre for Eco Energy Technologies, South-West University "Neofit Rilski", Blagoevgrad, Bulgaria \\ ${ }^{3}$ Department of Biochemistry and Microbiology, Plovdiv University, Plovdiv, Bulgaria \\ ${ }^{4}$ Department of Electrocatalysis and Electrocrystallization, Institute of Electrochemistry and Energy Systems \\ "Academician Evgeni Budevski”, Bulgarian Academy of Sciences (IEES-BAS), Sofia, Bulgaria
}

Received May 13, 2019; Accepted May 28, 2019

Microbial electrolysis cell (MEC) is an ecologically clean and innovative technology for hydrogen production. The development of cost-effective cathodes with high catalytic activity for hydrogen evolution reaction (HER) in nearneutral electrolytes is the most critical challenge for the practical application of MEC technology. In this study, graphite electrodes, functionalized with non-noble metal oxides, were produced and after electrochemical pre-treatment investigated as potential cathodes for MEC. The morphology of the developed materials was analyzed by scanning electron microscopy (SEM). Their electrochemical performance in neutral phosphate buffer solution (PBS) was explored by means of linear sweep voltammetry (LSV) and chronoamperometry (CA). The results from both methods show that all modified electrodes exhibit higher electrocatalytic activity towards HER than that of bare graphite, which is a prerequisite for further evaluation of these materials as cathodes in real MEC.

Keywords: modified graphite electrodes, hydrogen production, microbial electrolysis cell

\section{INTRODUCTION}

Hydrogen production is becoming increasingly important in view of using hydrogen in fuel cells. However, most of the production of hydrogen so far comes from the combustion of fossil fuels and water electrolysis, which have disadvantages like usage of non-renewable sources and high energy input.

Microbial electrolysis cell (MEC) is an ecologically clean, renewable and innovative technology for hydrogen production. MECs produce hydrogen mainly from waste biomass assisted by exoelectrogenic bacterial strains [1-4]. By adding a small electrical input (a minimum of $0.14 \mathrm{~V}$ compared to $1.23 \mathrm{~V}$ needed for water electrolysis) $[5,6]$ hydrogen can be evolved on the cathode. To date, carbon-based materials such as carbon cloth and carbon paper are applied in most MEC cathodes due to their stability in a microbial inoculum mixture, high conductivity and high specific surface area. However, they possess relatively low electrocatalytic activity for hydrogen evolution reaction (HER).

Crucial for the efficiency of MEC bio-hydrogen production is the choice of a proper cathodic catalyst [7]. Up to now, cathodes containing platinum have been mostly used in MECs $[8,9]$. The high cost and poisoning of $\mathrm{Pt}$ by different chemicals (e.g. sulfides) have driven researchers to investigate non-precious metal catalysts as an alternative. There is a gap in the knowledge about the catalytic activity of such materials towards hydrogen evolution under neutral medium and ambient temperature conditions, appropriate for microbial growth in MEC [10]. Therefore, the development of cost-effective cathodes for nearneutral $\mathrm{pH}$ and ambient temperature conditions is the most critical challenge for the practical application of MEC technology.

Transition metal-based catalysts are promising candidates in this respect, taking into consideration that the kinetics of the overall process in MEC is usually controlled by the relatively slow extracellular electron transfer from the biocatalyst (exoelectrogenic bacteria) to the anode. Depending on the precursors, different methods for preparation of supported metal catalysts are applied [11]. In the cases when metal oxides are used as precursors, they are usually transformed in dispersed metal catalysts by thermal treatment in hydrogen flow or reduction by a chemical reagent such as formaldehyde or hydrazine.

In this study we demonstrate a possibility for preparation of electrodes with good catalytic activity for HER in a neutral electrolyte by functionalization of graphite with non-precious metal oxides $\left(\mathrm{Fe}_{2} \mathrm{O}_{3}, \mathrm{Fe}_{3} \mathrm{O}_{4}, \mathrm{Mn}_{3} \mathrm{O}_{4}, \mathrm{TiO}_{\mathrm{x}}\right)$ and

\footnotetext{
* To whom all correspondence should be sent:

E-mail: elli_e1@swu.bg
} 
E. Chorbadzhiyska et al.: Modified graphite electrodes as potential cathodic electrocatalysts ...

subsequent electrochemical reduction. The morphology of the developed materials was characterized by means of scanning electron microscopy (SEM). Their electrocatalytic activity for HER in neutral phosphate buffer solution (PBS) was examined by means of linear sweep voltammetry (LSV) and chronoamperometry (CA).

\section{MATERIALS AND METHODS}

\section{Production and characterization of graphite-based electrodes}

Electrodes with geometric area of $1 \mathrm{~cm}^{2}$ were made using a procedure closely resembling the method used for producing synthetic graphite. The ingredients used were $50 \%$ finely powdered spectroscopic graphite, $30 \%$ carbon pitch with a softening point of $110{ }^{\circ} \mathrm{C}$ (Koppers Inc., USA) and $20 \%$ metal oxide $\left(\mathrm{Fe}_{2} \mathrm{O}_{3}, \mathrm{Fe}_{3} \mathrm{O}_{4}, \mathrm{Mn}_{3} \mathrm{O}_{4}\right.$ or $\left.\mathrm{TiO}_{\mathrm{x}}\right)$ as a catalyst precursor. The mixture was first homogenized in a rotary ball mill for 1 hour, then pressed at $250 \mathrm{MPa}$ in a stainless steel form and sintered for 30 minutes at $150{ }^{\circ} \mathrm{C}$. The electrode preforms were than pyrolyzed in argon at atmospheric pressure with a heating rate of $5{ }^{\circ} \mathrm{C} / \mathrm{min}$ and maintained at $800{ }^{\circ} \mathrm{C}$ for 1 hour. Titanium wires (1.6 $\mathrm{mm}$ thick) were screwed in the electrode samples and served as current collectors. The produced electrodes are further denoted as graphite, $\mathrm{Fe}_{2} \mathrm{O}_{3} /$ graphite, $\mathrm{Fe}_{3} \mathrm{O}_{4} /$ graphite, $\mathrm{Mn}_{3} \mathrm{O}_{4} /$ graphite and $\mathrm{TiO}_{\mathrm{x}} /$ graphite.

Before electrocatalytic tests, the as-prepared electrodes were pre-treated electrochemically in $100 \mathrm{mM}$ phosphate buffered saline (PBS, $\mathrm{pH}$ 7.4) by sweeping the potential with a scan rate of 1 $\mathrm{mV} / \mathrm{s}$ from 0 to $-1.2 \mathrm{~V}(v s$. $\mathrm{Ag} / \mathrm{AgCl}, 3 \mathrm{M} \mathrm{KCl})$ in order to reduce the incorporated metal oxide precursors.

The morphology of the developed materials was analyzed by scanning electron microscopy (SEM) using JEOL 6300.

\section{Electrocatalytic activity and corrosion behavior of the developed electrodes in PBS}

Investigations of the electrocatalytic activity and corrosion resistance of the developed electrodes were carried out in a three-electrode cell with 50 $\mathrm{cm}^{3}$ electrolyte volume. The tested sample was connected as a working electrode and a platinum wire was used as a counter electrode. All potentials were measured against $\mathrm{Ag} / \mathrm{AgCl}(3 \mathrm{M} \mathrm{KCl})$ reference electrode. The electrochemical studies were performed by using PalmSens 3 potentiostat/galvanostat, equipped with MUX8 multiplexer.
Linear sweep voltammetry (LSV) from 0 to -1.2 $\mathrm{V}$ (vs. $\mathrm{Ag} / \mathrm{AgCl})$ was performed to evaluate the electrocatalytic activity of the studied materials towards HER in neutral (PBS) solution. The potential was swept with a scan rate of $1 \mathrm{mV} / \mathrm{s}$. LSV tests were carried out in duplicate and the second scan was used for analysis of performance based on the voltage needed to initiate hydrogen production, $\mathrm{V}_{\mathrm{e}}$, and the slope in the voltammogram, $\mathrm{V}_{\mathrm{h}}$, reflecting the current (resp. hydrogen) production rate at an applied voltage. The linear region in the LSVs was analyzed by linear regression to obtain the value of $\mathrm{V}_{\mathrm{e}}$ and the slope $\mathrm{V}_{\mathrm{h}}$.

Chronoamperometric measurements were also carried out at $-1.0 \mathrm{~V}$ (vs. $\mathrm{Ag} / \mathrm{AgCl}$ ) for $10 \mathrm{~min}$ and the responding current was monitored. The quantity of the produced hydrogen was calculated by integration of the areas under the chronoamperometric curves, applying the Faraday's law.

The corrosion stability of the newly produced electrodes in used neutral electrolyte was examined by anodic polarization with a scan rate of $1 \mathrm{mV} / \mathrm{s}$ from -0.6 to $+0.2 \mathrm{~V}$ ( $v s$. $\mathrm{Ag} / \mathrm{AgCl}$ ). The corrosion tests with each electrode were performed before and after cathodic pre-treatment. The obtained data are presented as Tafel plots, from which the values of the corresponding corrosion potentials, $E_{\text {corr., }}$, and corrosion currents, $I_{\text {corr. }}$, are estimated.

\section{RESULTS AND DISCUSSION}

After preparation of electrodes, their morphology was analyzed by scanning electron microscopy. The obtained micrographs are presented in Figure 1. The SEM images reveal that the produced materials consist of big conglomerates, in which particles of the metallic catalyst precursors are incorporated. In all cases, the distribution of these particles is not uniform, having different forms and size.

As a result of the electrochemical pre-treatment, the incorporated metal oxide precursors undergo reduction, which is obviously seen from the voltammograms obtained during the performed procedure (Fig. 2). The cathodic peak obtained with non-modified graphite could be assigned to reduction of impurities (e.g. organic compounds) on the electrode surface. Having in mind that the produced materials possess bulk 3D-structure without macropores, most probably only the particles on the electrode surface, exposed to the electrolyte, are partially reduced as a result of the applied electrochemical procedure. Nevertheless, this leads to a change in the corrosion behavior illustrated on Fig. 3 and summarized in Table 1. 
E. Chorbadzhiyska et al.: Modified graphite electrodes as potential cathodic electrocatalysts ...

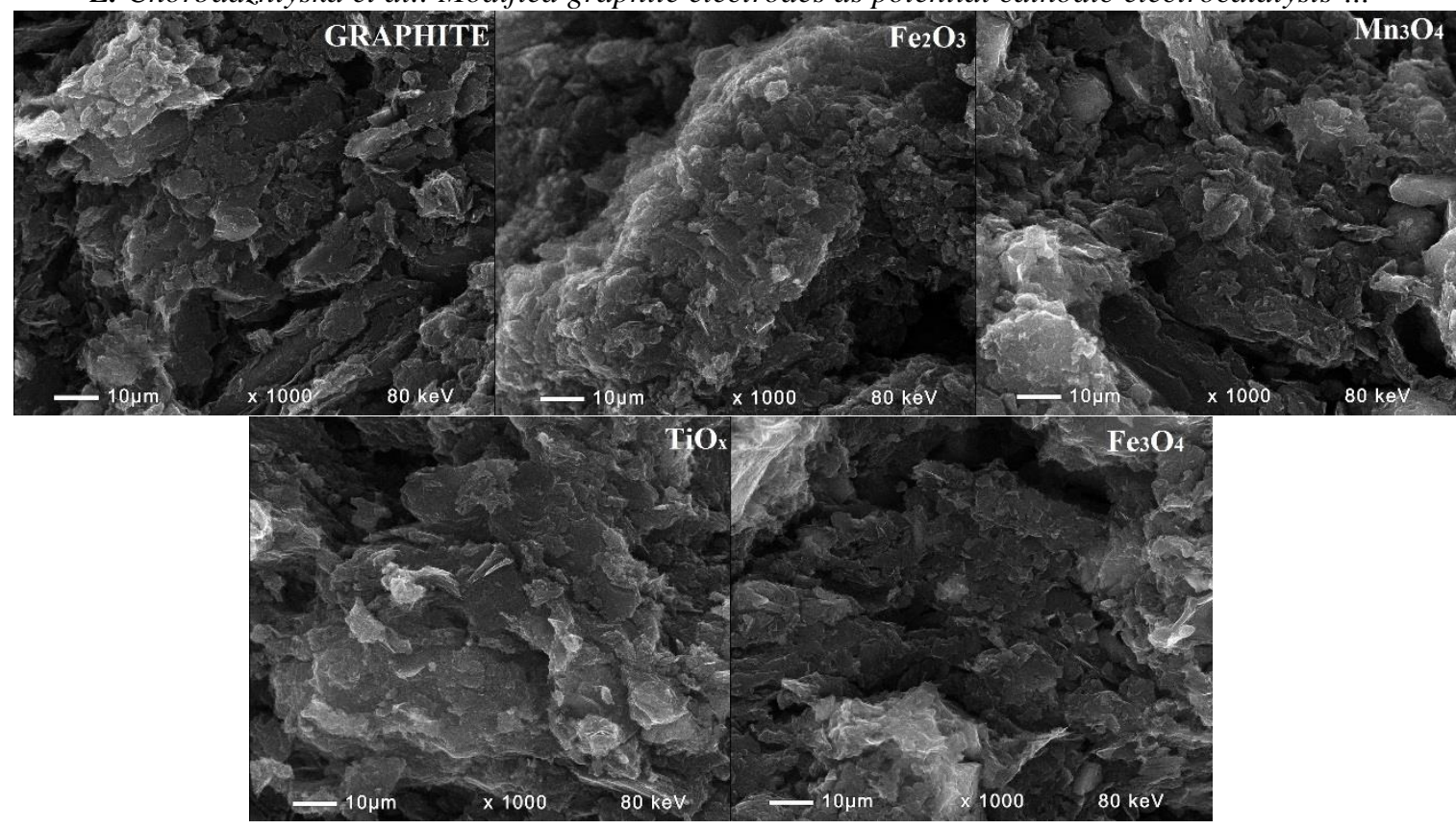

Fig. 1. SEM images of produced electrode materials

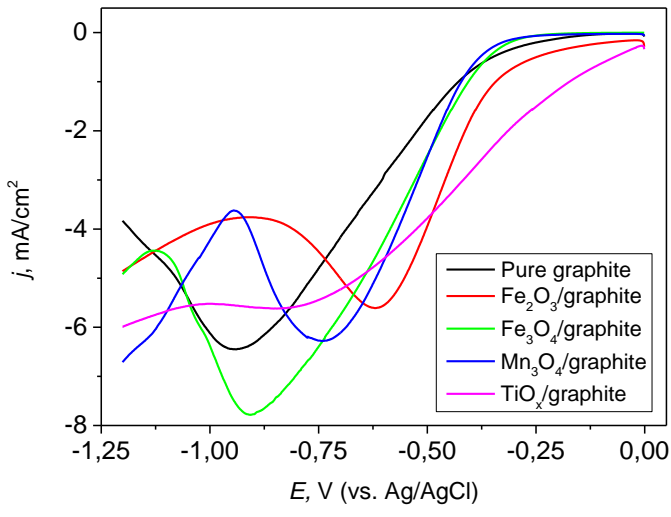

Fig. 2. Linear voltammograms obtained during cathodic pre-treatment of investigated electrodes.

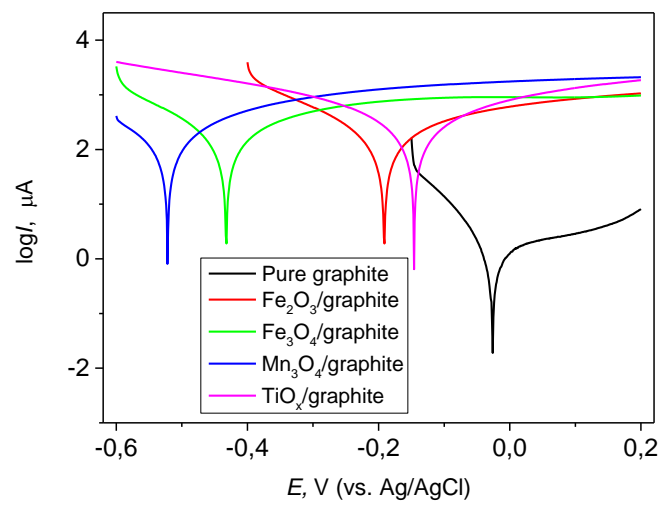

Fig. 3. Tafel plots of modified and non-modified graphite electrodes after cathodic pre-treatment.

Table 1. Values of the corrosion potential, $E_{\text {corr. }}$, and corrosion current density, $j_{\text {corr }}$ derived from Tafel plots, obtained with the investigated materials before and after cathodic pre-treatment.

\begin{tabular}{|c|c|c|c|c|}
\hline \multirow{2}{*}{ Material } & \multicolumn{2}{|c|}{ Before cathodic pre-treatment } & \multicolumn{2}{c|}{ After cathodic pre-treatment } \\
\cline { 2 - 5 } & $\mathrm{E}_{\text {corr }}, \mathrm{V}$ & $\mathrm{j}_{\text {corr }}, \mu \mathrm{A} . \mathrm{cm}^{-2}$ & $\mathrm{E}_{\text {corr }}, \mathrm{V}$ & $\mathrm{j}_{\text {corr }}, \mu \mathrm{A} . \mathrm{cm}^{-2}$ \\
\hline Graphite & +0.015 & 0.04 & -0.026 & 1.10 \\
\hline $\mathrm{Fe}_{2} \mathrm{O}_{3} /$ graphite & +0.043 & 9.77 & -0.190 & 143.55 \\
\hline $\mathrm{Fe}_{3} \mathrm{O}_{4} /$ graphite & -0.002 & 0.87 & -0.429 & 140.93 \\
\hline $\mathrm{Mn}_{3} \mathrm{O}_{4} /$ graphite & +0.002 & 10.27 & -0.522 & 70.96 \\
\hline $\mathrm{TiO}_{\mathrm{x}} /$ graphite & -0.070 & 21.42 & -0.145 & 149.97 \\
\hline
\end{tabular}

The inhomogeneity of the modified electrodes due to incorporation of metal oxides in the graphite matrix results in their lower corrosion resistance in comparison with the bare graphite electrodes. The surface reduction of the metal oxides as a result of the cathodic pre-treatment is confirmed by the shift of the corrosion potentials in negative direction, as

well as by the increase in corrosion currents, indicating existence of much more particles in lower oxidation state. In both cases (before and after pre-treatment), the electrodes modified with 
E. Chorbadzhiyska et al.: Modified graphite electrodes as potential cathodic electrocatalysts ... $\mathrm{TiO}_{\mathrm{x}}$ exhibit the highest corrosion rate, resp. the

Table 2. Values of the minimum voltage needed to initiate substantial current $\mathrm{V}_{\mathrm{e}}$ and hydrogen production rate $\mathrm{V}_{\mathrm{h}}$, derived from linear voltammograms obtained with the investigated materials

\begin{tabular}{|c|c|c|}
\hline Electrode & $\mathrm{V}_{\mathrm{e}}, \mathrm{mV}(\mathrm{vs}$. & $\mathrm{V}_{\mathrm{h}}, \mathrm{mA} / \mathrm{V}$ \\
\hline Graphite & -0.65 & 2.65 \\
\hline $\mathrm{Fe}_{2} \mathrm{O}_{3} /$ graphite & -0.42 & 3.00 \\
\hline $\mathrm{Fe}_{3} \mathrm{O}_{4} /$ graphite & -0.48 & 4.58 \\
\hline $\mathrm{Mn}_{3} \mathrm{O}_{4} /$ graphite & -0.40 & 5.44 \\
\hline $\mathrm{TiO}_{\mathrm{x}} /$ graphite & -0.44 & 4.98 \\
\hline
\end{tabular}

After pre-treatment, the electrodes were tested in respect to electrocatalytic activity towards HER by means of LSV and CA.

The lack of cathodic peaks on the linear voltammograms (Fig. 4) indicates that no other reduction reaction except HER takes place on the produced electrodes after their initial pre-treatment. The values of $V_{e}$ and $V_{h}$ (Table 2), derived from the LVs, show that the applied modification decreases the HER overpotential and at the same time enhances the hydrogen production rate. The minimum potental $\left(\mathrm{V}_{\mathrm{e}}\right)$ needed to initiate substantial current obtained with bare graphite is $0.65 \mathrm{~V}$, while for all modified electrodes it ranges between $-0.40 \mathrm{~V}$ and $-0.48 \mathrm{~V}$ (vs. $\mathrm{Ag} / \mathrm{AgCl})$. As seen from the data, the highest $\mathrm{V}_{\mathrm{h}}$ and the lowest $\mathrm{V}_{\mathrm{e}}$ values, revealing the best catalytic performance [12], are achieved with $\mathrm{Mn}_{3} \mathrm{O}_{4}$ /graphite electrode.

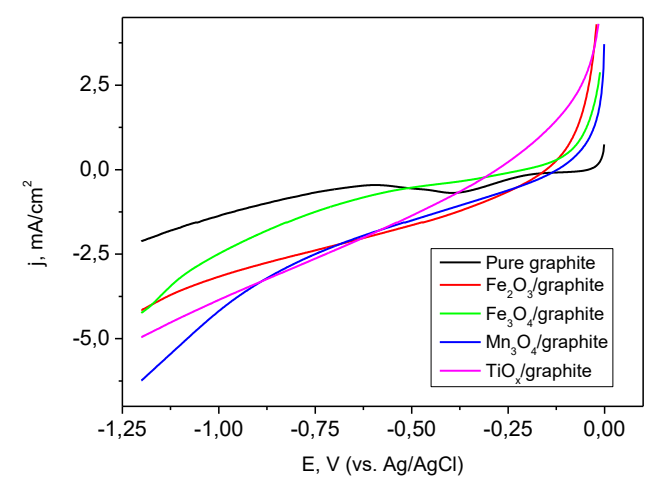

Fig. 4. Linear voltammograms obtained with modified electrodes in neutral PBS; scan rate $1 \mathrm{mV} / \mathrm{s}$.

The results from the chronoamperometric measurements confirm those obtained by LSV. The steady-state currents (Fig. 5a) and the corresponding hydrogen production rates (Fig. $5 b$ ) achieved with all modified materials are 2 to 4 times higher than that obtained with bare graphite. The highest hydrogen production rate of $1.6 \mathrm{ml} . \mathrm{cm}^{-}$ ${ }^{2} \cdot \mathrm{h}^{-1}$ is achieved with $\mathrm{Mn}_{3} \mathrm{O}_{4}$-modified electrode. The rest of the studied electrodes, except lowest corrosion resistance.

$\mathrm{Fe}_{2} \mathrm{O}_{3}$ /graphite and $\mathrm{Fe}_{3} \mathrm{O}_{4} /$ graphite, arrange in the same order determined by LSV tests. The achieved values of hydrogen production rate with the modified electrodes in this study are comparable with those obtained with other supported non-noble metal catalysts [13] and even with Pd-Au [14], examined at similar experimental conditions.
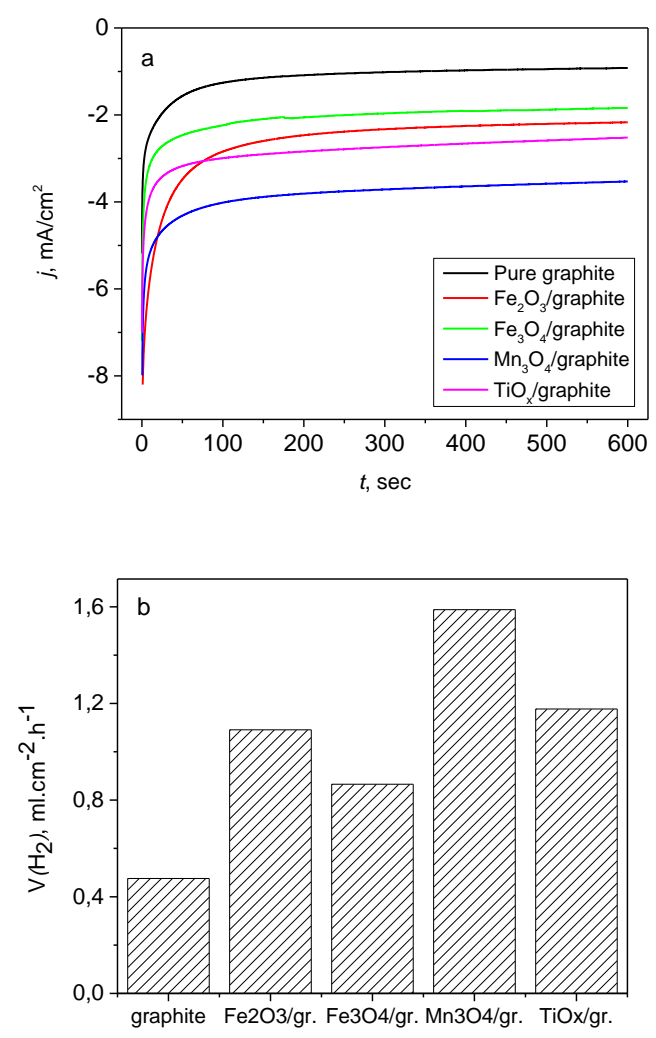

Fig. 5. a) Chronoamperograms obtained at $-1.0 \mathrm{~V}$ (vs. $\mathrm{Ag} / \mathrm{AgCl}$ ) with the investigated electrodes; b) Hydrogen evolution rate estimated from the chronoamperograms.

\section{CONCLUSIONS}

The results from this study show that costeffective electrodes with high electrocatalytic activity for HER in neutral electrolyte can be produced from non-precious metal oxides precursors mixed with graphite, and subsequent electrochemical reduction. From all tested graphite electrodes modified with $\mathrm{Fe}_{2} \mathrm{O}_{3}, \mathrm{Fe}_{3} \mathrm{O}_{4}, \mathrm{Mn}_{3} \mathrm{O}_{4}$ or $\mathrm{TiO}_{\mathrm{x}}$, the highest hydrogen production rate was achieved with the $\mathrm{Mn}_{3} \mathrm{O}_{4}$ /graphite. Further studies, aiming at practical application of this type of electrodes as cathodes in MECs, are going to be performed.

Acknowledgements: This study was funded by the National Science Fund of Bulgaria through Contract DM 09/3/2016 and partially supported by National Science Program Eplus (Contract D01214/2018). The authors are grateful to 
E. Chorbadzhiyska et al.: Modified graphite electrodes as potential cathodic electrocatalysts ...

Koppers International B.V. for providing free samples of their Carbon Pitch.

\section{REFERENCES}

1. H. Liu, S. Grot, B. Logan, Environ. Sci. Technol., 39, 4317 (2005).

2. R. Rozendal, H. Hamelers, G. Euverink, S. Metz, C. Buisman, Int. J. Hydrogen Energy., 31, 1632 (2006).

3. B. Logan, D. Call, S. Cheng, H. Hamelers, T. Sleutels, A. Jermiasse, et al., Environ. Sci. Technol., 42, 8630 (2008).

4. B. Logan, Microbial fuel cells, New York: Wiley; 2007.

5. J. Ditzig, H. Liu, B. Logan, Int. J. Hydrogen Energy, 32, 2296 (2007).

6. A. Kadier, Y. Simayi, M. Kalil, P. Abdeshahian, A. Hamid, Renew. Energy, 71, 466 (2014).
7. B. Conway, B. Tilak, Electrochim. Acta, 47, 357 (2002).

8. R. Rozendal, H. Hamelers, K. Rabaey, J. Keller, Trends Biotechnol., 26, 450 (2008).

9. B. Tartakovski, M. Manuel, H. Wang, S. Guiot, Int. J. Hydrogen Energy, 34, 672 (2009).

10. C., Santoro, F., Soavi, C., Arbizzani, A., Serov, S., Kabir, K., Carpenter, O., Bretschger, P., Atanassov, Electrochim. Acta, 220, 672 (2016).

11. F. Pinna, Catalysis Today, 41, 129 (1998).

12. Y. Zhang, M. Merrill, B. Logan, Int. J. Hydrogen Energy, 35, 12020 (2010).

13. M. Mitov, E. Chorbadzhiyska, L. Nalbandian, Y. Hubenova, J. Power Sources, 356, 467 (2017).

14. E Chorbadzhiyska, M Mitov, L Nalbandian, Y Hubenova, Int. J. Hydrogen Energy, 40, 7329 (2015). 